\title{
Morfologia do funículo espermático em caprinos da raça Bhuj Brasileira1
}

\author{
Luis A.O. P. Costa ${ }^{2}$, Marcelo Abidu-Figueiredo ${ }^{2 *}$, Clarice Machado-Santos ${ }^{3}$, \\ Vicente Borelli ${ }^{4}$ e João G. L. Pereira ${ }^{4}$
}

\begin{abstract}
Costa L.A.O.P., Abidu-Figueiredo M., Machado-Santos C., Borelli V. \& Pereira J.G.L. 2011. [Morphology of the spermatic cord in Brazilian Bhuj goats.] Morfologia do funículo espermático em caprinos da raça Bhuj Brasileira. Pesquisa Veterinária Brasileira 31(8):711717. Departamento de Anatomia Animal, Instituto de Biologia, Universidade Federal Rural do Rio de Janeiro, Seropédica, RJ 23890-000, Brazil. E-mail: marceloabidu@gmail.com

Histological aspects of the spermatic cord were studied in 40 Brazilian Bhuj goats. It was seen that the spermatic cord is involved by a thin capsule of compact connective tissue recovered by mesothelium which forms an expansion, the mesodeferens. Under this capsule is a subcapsular layer of variable thickness, formed by loose elastic fiber connective tissue that mixes with deep layer of the mesodeferens and with the adventitia of ductus deferens. Between the testicular artery and testicular veins exists an intervascular compact elastic fiber connective tissue in continuity with the adventitia of spermatic cord vessels. In the abdeferential region of the spermatic cord exists a neurovascular contingent, the vessels of which generally have inferior calibers and similar constitution and arrangement as the testicular artery and veins; the described contingent is related to nutrition of the initial portion of ductus deferens and part of the epididymis head and body. The vascular arrangement shows that the segment of the testicular artery in the spermatic cord has a sinuous disposition and is totally involved by the venous plexus formed by testicular vein valves with irregular outlines, diverse calibers and large connections. The length of the intra spermatic cord segment of the testicular artery has a medium and standard deviation of $134.6 \pm 38.1 \mathrm{~cm}$ on the right and $137 \pm 33.9 \mathrm{~cm}$ on the left. There were no statistical differences between the right and left medium ranges.
\end{abstract}

INDEX TERMS: Morphology, spermatic cord, arteries, veins, Bhuj goats.

RESUMO.- Estudamos em 40 caprinos adultos da raça Bhuj Brasileira os aspectos histológicos do funículo espermático. Observamos que este se acha envolvido por uma cápsula de tecido conjuntivo fibroelástico denso, de espessura variável, pregueada em alguns pontos, e revestida por mesotélio que circunda todo o conjunto vásculo-nervoso, e projeta-se para formar o mesoducto deferente. Em posição subcapsular, verifica-se uma camada de tecido conjuntivo fibroelástico frouxo, de espessura variável, que circunda parcialmente o funículo

\footnotetext{
${ }^{1}$ Recebido em 1 de Julho de 2010.

Aceito para publicação em 5 de fevereiro de 2011.

${ }^{2}$ Departamento de Biologia Animal, Área de Anatomia Animal, Universidade Federal Rural do Rio de Janeiro (UFRRJ), BR $465 \mathrm{Km}$ 7, Seropédica, RJ 23890-000, Brasil. *Autor para correspondência: marceloabidu@gmail.com

${ }^{3}$ Pós-Graduação em Biologia Animal, Laboratório de Histologia e Embriologia, Instituto de Veterinária, sala 85, UFRRJ, Seropédica, RJ.

${ }^{4}$ Departamento de Cirurgia, Faculdade de Medicina Veterinária e Zootecnia (FMVZ), Universidade de São Paulo (USP), Av.Prof. Dr. Orlando Marques de Paiva 87, Cidade Universitária, São Paulo, SP 05508-000, Brasil.
}

espermático, isolando nas regiões deferencial e abdeferencial, conjuntos vásculo-nervosos, responsáveis pela nutrição do epidídimo. Na região do mesoducto deferente, o tecido subcapsular acompanhado de tecido adiposo constitui a camada interna deste meso, formando a sua adventícia e abrigando vasos e nervos deferenciais. Na região abdeferencial, pequenos acúmulos de tecido adiposo são vistos de permeio aos vasos e nervos desta região. Entre as artérias, veias e nervos testiculares, bem como entre os vasos das regiões deferencial e abdeferencial, observa-se o tecido conjuntivo denso, intervascular, rico em fibras elásticas, que constitui as adventícias contínuas destes vasos. 0 arranjo vascular mostra que o segmento da artéria testicular, contido no funículo espermático, apresenta trajeto sinuoso. Estando envolvido pelo plexo venoso pampiniforme, formado por veias testiculares desprovidas de válvulas de calibres variados, apresentando amplas comunicações entre si. As veias responsáveis pela drenagem do epidídimo e ducto deferente estão localizadas em posição subcapsular deferencial e abdeferencial e mostram-se providas de vál- 
vulas. 0 trato das artérias testiculares no funículo espermático apresenta como média e desvio padrão $134,6 \pm 38,1 \mathrm{~cm}$ à direita, e $137,0 \pm 33,9 \mathrm{~cm}$ à esquerda, não existindo diferenças estatisticamente significantes ao nível de $5 \%$, quando comparamos a média do segmento da artéria testicular contida no funículo espermático direito em relação ao esquerdo.

TERMOS DE INDEXAÇÃO: Morfologia, funículo espermático, artérias, veias, caprinos, Bhuj Brasileira.

\section{INTRODUÇÃO}

Os caprinos da raça Bhuj provenientes do Golfo de Kutchi, extremo Oeste da Índia, foram introduzidos no Nordeste do Brasil onde foram cruzados com animais Anglo-nubiano dando origem a raça Bhuj brasileira (Medeiros et al. 1982). A raça Bhuj já foi campeã de vendas no Brasil, na década de 1970 e início de 1980. Hoje existem poucos rebanhos puros no Brasil, podendo se destacar o da Bahia.

A espermatogênese está sob o controle fisiológico do sistema neuroendócrino e sofre influência direta da termorregulação escroto-testicular (Courot \& Ortavant 1981, Byers \& Glover 1984, Dukes 2006). Na maioria dos mamíferos, os testículos acham-se localizados no escroto onde encontram as condições ideais de temperatura para a espermatogênese (Nickel et al. 1979, Hafez 2004). A termorregulação acontece principalmente pela existência de três mecanismos: as glândulas apócrinas, situadas no escroto, permitem a sudação com subseqüente resfriamento testicular; a túnica dartos e o músculo cremáster que favorecem o afastamento e a aproximação dos testículos à região inguino-abdominal e o plexo pampiniforme, constituído por artérias e veias testiculares, dispostas contiguamente, o qual é responsável pela troca de calor e conseqüente resfriamento do sangue arterial (Villares 1976, Dukes 2006). A termoregulação também pode ser influenciada por fatores como grau de bipartição escrotal e fatores climáticos envolvendo período seco e chuvoso (Machado-Junior et al., 2009).

0 sangue procedente do organismo animal realiza na altura do funículo espermático trocas térmicas, para que ocorra o decréscimo da temperatura sangüínea, necessária ao fenômeno da espermatogênese (Nickel et al. 1979, Hafez 2004). O funículo espermático, dependendo da espécie, apresenta condições morfológicas adequadas ao desempenho desta função, porém, estas estruturas apresentam particularidades que variam segundo a espécie e raça.

Pela importância dos elementos anatômicos que integram o funículo espermático no mecanismo de termorregulação testicular, o objetivo deste estudo foi analisar os aspectos histológicos dos envoltórios dos vasos, nervos e dos tecidos intervasculares, bem como o arranjo do sistema vascular e o comprimento do segmento da artéria testicular contido no funículo espermático de caprinos adultos da raça Bhuj Brasileira. Assim, pretendendo com estes dados contribuir com as ciências morfológicas, tanto sob os aspectos da micro e da macroscópicos da anatomia comparativa.

\section{MATERIAL E MÉTODOS}

Foram utilizados 40 pares de testículos com os seus respectivos funículos espermáticos de caprinos da raça Bhuj Brasileira adultos procedentes de várias regiões do Nordeste Brasileiro e abatidos em Natal, Rio Grande do Norte. Logo após o sacrifício dos animais foram retiradas as estruturas anexas ao funículo, ou seja, o escroto e os correspondentes testículos e epidídimos. Para o estudo anatômico da angioarquitetura o material foi acondicionado em caixas isotérmicas de isopor contendo gelo e para o estudo histológico foram realizados cortes transversais de $5 \mathrm{~cm}$ de espessura, separados das porções dorsal, média e ventral de 5 pares de funículos espermáticos, totalizando 30 segmentos fixados por 24 horas em líquido de Bouin. Todo material foi conduzido ao Departamento de Cirurgia e Obstetrícia da FMVZ-USP.

Os segmentos foram processados pela técnica histológica de rotina para inclusão em parafina. Os cortes foram feitos com $5 \mu \mathrm{m}$ de espessura e corados pela hematoxilina e eosina para verificar a integridade tecidual, tricrômico de Mallory (fibras colágenas), orceína nítrica (fibras elásticas) e reticulina de Gordon (fibras reticulares).

Os arranjos vasculares dos funículos espermáticos foram examinados em 6 modelos, correspondentes a 5 pares de testículos que obtivemos com solução de acetato de vinil (Solvent Vinyl, VMCH B, 1099), corada (Laca nitrocelulose vermelho molibdato). Para tanto, isolamos e canulamos as artérias testiculares imediatamente antes de alcançarem o funículo espermático e uma das veias testiculares localizadas na região ventral subalbugínea do órgão. A seguir, procedemos à limpeza desses sistemas vasculares, injetando inicialmente solução salina seguida por injeção de acetona. Posteriormente injetou-se cerca de $5 \mathrm{ml}$ de acetato de vinil corado em vermelho $( \pm 4 \mathrm{ml})$ na artéria testicular e em azul $( \pm 5 \mathrm{ml})$ em uma das veias testiculares. Submetemos depois estas preparações à ação do ácido sulfúrico a 30\% durante 72-96 horas, para, com auxílio de finos e controlados jatos de água, obter os moldes, que também foram fotografados para respectiva documentação.

Medimos em 60 modelos o comprimento do trato da artéria testicular contida no funículo espermático, que conseguimos com solução de Neoprene látex 450 corada com pigmento específico, correspondente a 30 pares de testículos e respectivos funículos espermáticos. Para tanto, após o descongelamento das peças em água corrente por período de aproximadamente 5 horas, isolamos, canulamos e injetamos a artéria testicular antes da formação do funículo espermático, com solução de Neoprene látex 450 $( \pm 3 \mathrm{ml})$, até alcançar o testículo. Submetemos, a seguir, estas preparações à ação do ácido sulfúrico a $30 \%$ durante o período de 72-96 horas e, com auxílio de finos e controlados jatos de água, separamos os modelos, que, encaixados, sem sofrer estiramento, em sulcos de aproximadamente $2 \mathrm{~cm}$ de espessura realizados em sarrafo de madeira de $50 \mathrm{~cm}$ de comprimento por $5 \mathrm{~cm}$ de largura e $2 \mathrm{~cm}$ de espessura, onde adaptamos régua milimetrada, nos permitiu a identificação do comprimento segmento vascular retificado.

Foi calculada a média e o desvio padrão do comprimento da artéria testicular direita e esquerda. Para a comparação dos valores obtidos para cada artéria foi utilizado o Teste t não pareado com intervalo de confiança de 95\%, considerando pd"0,05 como significativo. A análise estatística foi realizada através do Softawers Graphpad Instat.

\section{RESULTADOS}

O funículo espermático de caprinos da raça Bhuj adultos possui uma fina cápsula de tecido conjuntivo fibroelástico denso circundando o conjunto vásculo-nervoso, que se projeta para formar mesodeferente. Esta fina cápsula, em cuja espessura encontramos vasos e nervos, possui revestimento mesotelial (Fig.1A), que representa o folheto visceral da túnica vaginal, 


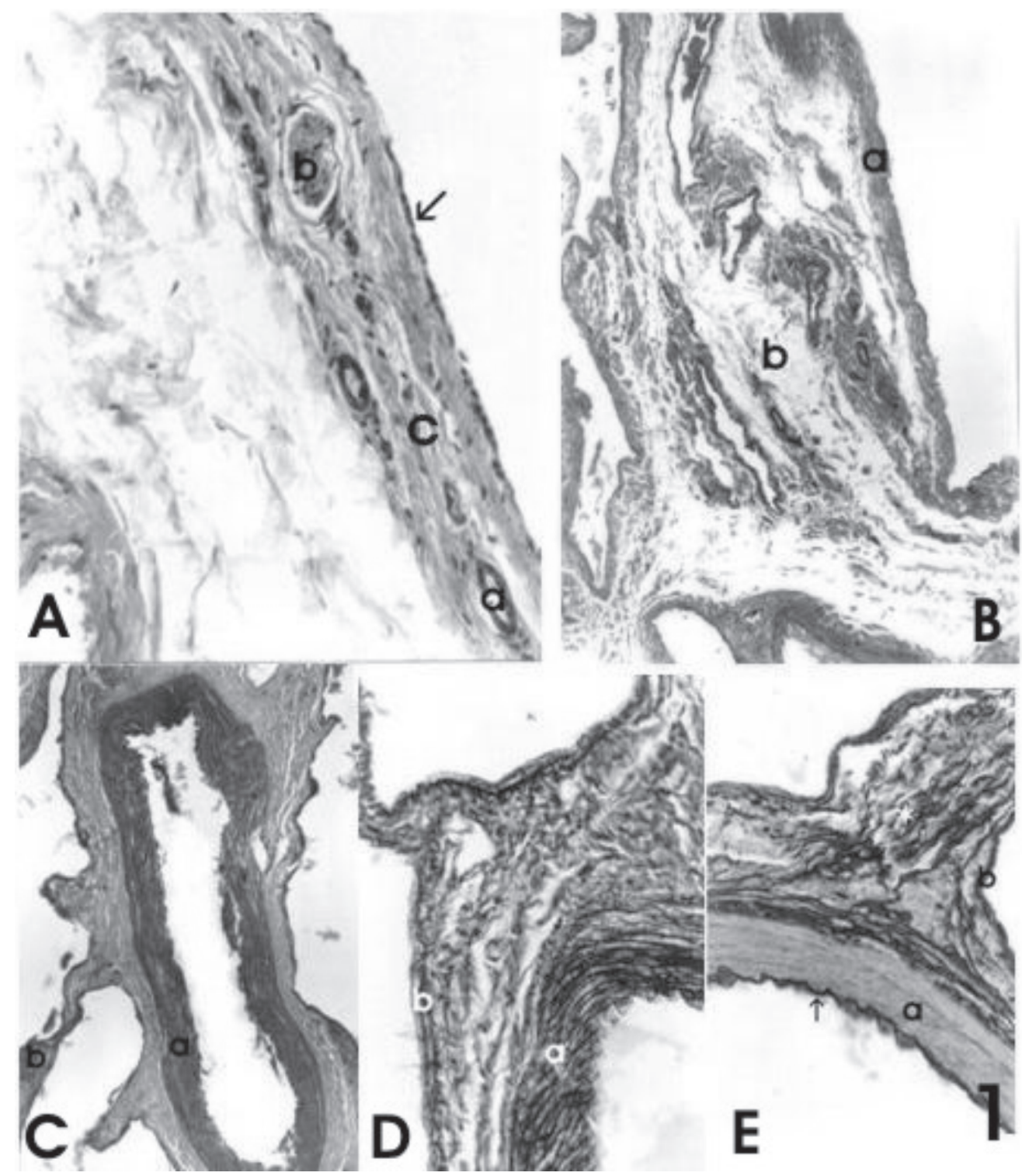

Fig.1. Porção média do funículo espermático de caprinos da raça Bhuj. (A) Observar cápsula de tecido conjuntivo fibroelástico denso (c) com revestimento mesotelial (!), vaso (a) e nervo (b) intracapsular. HE, 200x. (B) Cápsula (a) e camada subcapsular (b) constituída por tecido conjuntivo frouxo. HE, 80x. (C) Túnica média da artéria testicular constituída por células musculares lisas (a) e veias testiculares (b). Tricrômico de Mallory 80x. (D) Rede de fibras reticulares na túnica média da artéria testicular (a) e nas veias testiculares (b). Orceína nítrica, 200x. Reticulina de Gordon. (E) Túnica intima da artéria testicular com limitante elástica interna espessa (seta), túnica média (a). Notar veia testicular (b) e tecido conjuntivo fibroelástico denso intervascular $(*)$. Orceína Nítrica, 200x.

observado em quase toda a extensão do funículo espermático, exceção feita à região de reflexão dessa serosa, que passa a constituir o folheto parietal da túnica vaginal.

A camada subcapsular, de espessura variável é constituída por tecido conjuntivo frouxo, apresentando vasos e nervos (Fig.1B); na região abdeferencial, pequenos acúmulos de tecido adiposo, bem como vasos linfáticos calibrosos. 0 tecido subcapsular constitui também a camada interna do mesodeferente, assim como a adventícia deste ducto.

Abaixo da camada subcapsular observamos o tecido conjuntivo fibroelástico denso com algumas arteríolas, vênulas e nervos, que corresponde ao tecido intervascular do funículo espermático, continuando-se com as adventícias dos vasos funiculares, sem destacar alguma delimitação entre os vasos.

As secções da artéria testicular que aparecem separadas entre si pelo tecido conjuntivo intervascular são oblíquas, indicando o trajeto sinuoso deste vaso, apresentando túnica média constituída por células musculares lisas (Fig.1C), sustentadas por delicada rede de fibras reticulares (Fig.1D) e ocasionais fibras elásticas. A lâmina elástica limitante interna deste vaso é espessa e conspícua enquanto a adventícia, embora rica em fibras elásticas, não se distingue precisamente do tecido intervascular adjacente (Fig.1E).

O complexo venoso do funículo espermático caracteriza- 


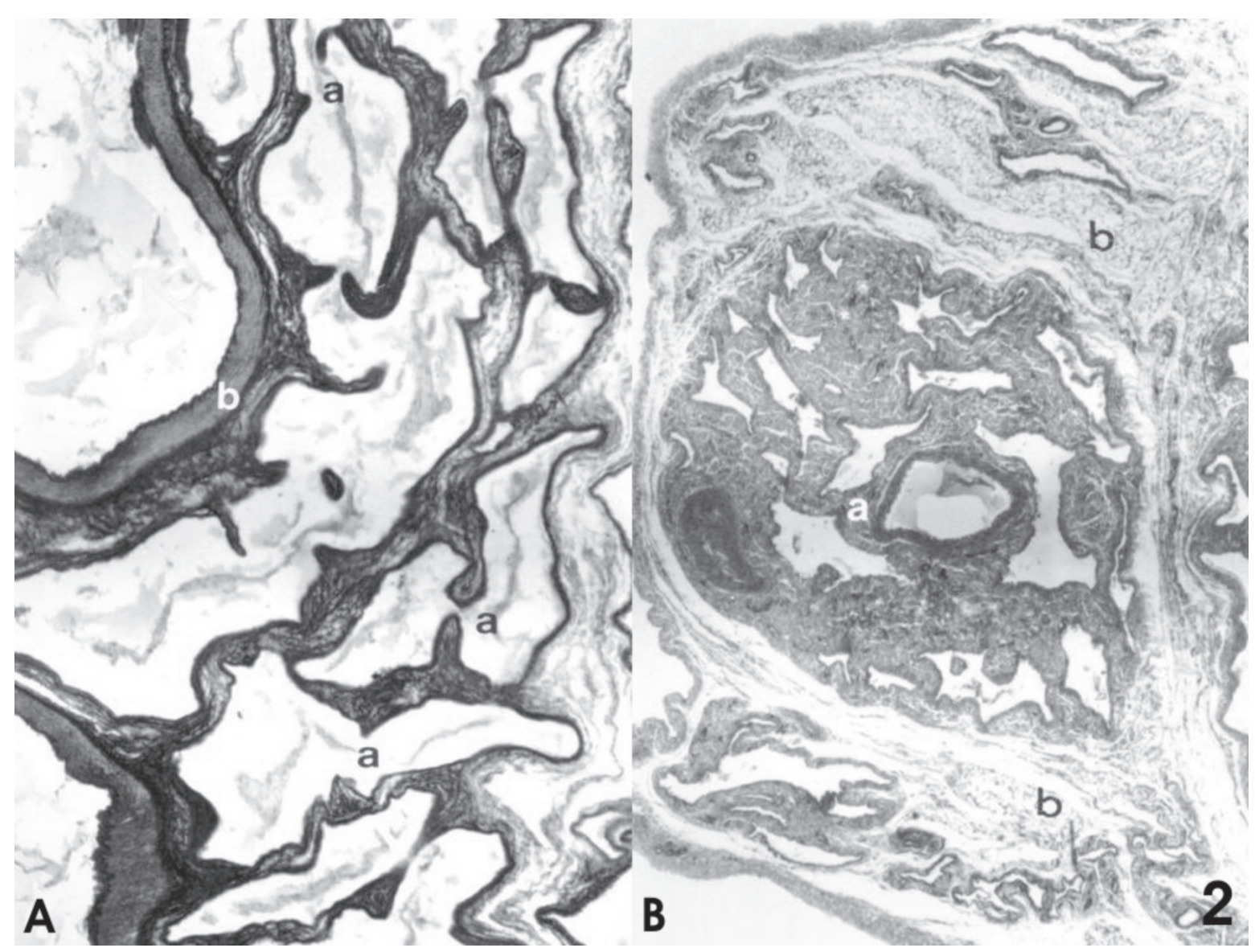

Fig.2. (A) Complexo venoso do funículo espermático. Intercomunicação das veias testiculares (a) circundando a artéria testicular (b). Orceína Nítrica, 30x. (B) Conjunto vasculo-nervoso (a) da região abdeferencial do funículo espermático circundado por tecido conjuntivo fibroelástico frouxo (b). HE, 30x.

se por envolver completamente a artéria testicular, apresentando-se desprovido de válvulas e com amplas comunicações entre si (Fig.2A). Estas veias mostram túnica média delgada formada por fibras musculares lisas, sustentadas por fibras reticulares entremeadas com fibras elásticas. As adventícias destes vasos, à semelhança das artérias, acham-se também constituídas por tecido fibroelástico denso, que se continua com o tecido intervascular (Fig.1E).

Na região abdeferencial do funículo espermático, separado pelo tecido conjuntivo fibroelástico frouxo subcapsular e envolvido parcialmente por tecido adiposo, arteríolas, vênulas, nervos e amplos linfáticos, evidenciamos um conjunto vásculo-nervoso, cujos componentes, embora geralmente de menor calibre, mostram constituição e arranjo semelhante ao da artéria e veias testiculares (Fig.2B).

0 estudo da arquitetura do funículo espermático, realizado em modelos obtidos com a injeção dos vasos com solução de acetato de vinil, mostra que, este funículo, nos caprinos da raça Bhuj, apresenta forma cônica, cuja base assenta sobre a extremidade dorsal (capitata) do testículo (Fig.3A).

0 segmento funicular da artéria testicular encontra-se totalmente envolvido e entremeado com o plexo venoso funicular, apresentando disposição tortuosa em todo o seu trajeto (Fig.3B).

As veias testiculares confluem para a extremidade dorsal (capitata) do testículo, onde, mediante inúmeras anastomo- ses, passam a constituir o plexo venoso pampiniforme, perdendo estes vasos a sua individualidade, e envolvendo completamente o segmento funicular da artéria testicular.

Percorrendo a região cranial do funículo espermático, encontramos um complexo vásculo-nervoso implicado na nutrição da cabeça e parte do corpo do epidídimo, cuja artéria apresenta também arranjo sinuoso, entremeada com as veias que mostram inúmeras anastomoses. Este contingente vásculo-nervoso corresponde ao encontrado histologicamente na região abdeferencial do funículo, envolvido pelas cápsulas de tecido conjuntivo fibroelástico denso e frouxo.

Junto à região medial do funículo, identificamos a artéria, as veias, e os nervos que participam do suprimento da porção inicial do duto deferente, parte do corpo e cabeça do epidídimo.

0 estudo das preparações do segmento arterial, realizados com Neoprene látex 450, revela que o segmento da artéria testicular contida no funículo espermático, devidamente retificados, mostra que nos caprinos adultos da raça Bhuj estes vasos são sempre únicos e apresentam respectivamente, como média e desvio padrão $134,6 \pm 38,1 \mathrm{~cm}$ à direita $\mathrm{e}$ $137,0 \pm 33,9 \mathrm{~cm}$ à esquerda (Fig.4). A análise estatística destes resultados revela não existir diferenças significativas com intervalo de confiança de 95\%, ao compararmos a média do segmento da artéria testicular contida no funículo espermático direito em relação ao esquerdo $(p=0,7978)$. 


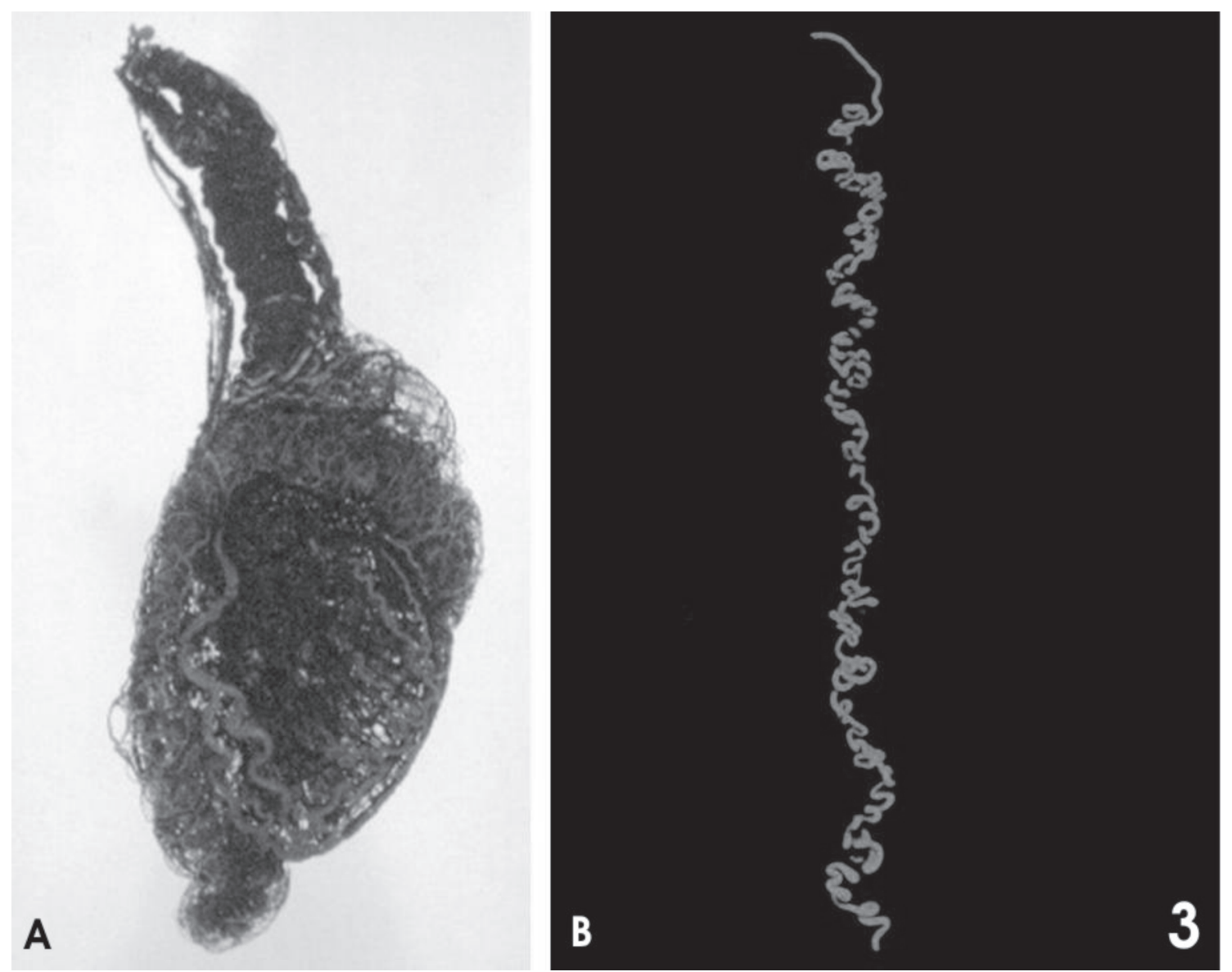

Fig.3. (A) Fotomacrografia da face lateral do modelo de "vinil" das veias e artérias testiculares de caprino da raça Bhuj Brasileira. (B) Modelo de Neoprene látex "450" de segmento da artéria testicular de caprino adulto, da raça Bhuj Brasileira, contido no funículo espermático.

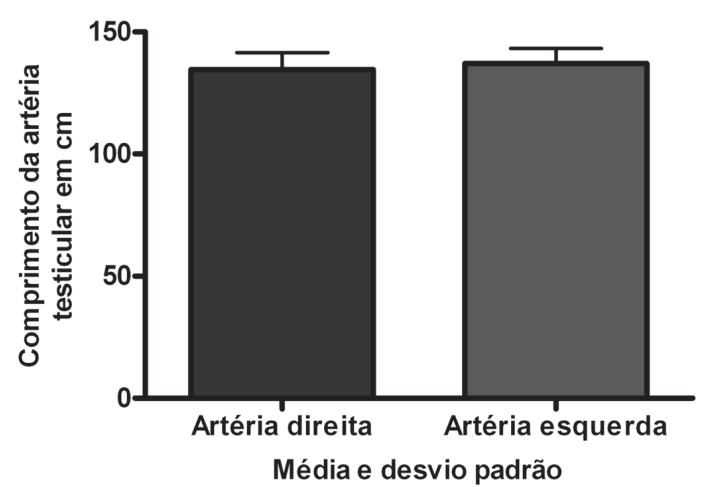

Fig.4. Média e desvio padrão do comprimento da artéria testicular direita e esquerda nos caprinos adultos da raça Bhuj Brasileira.

\section{DISCUSSÃO}

O exame dos cortes histológicos dos funículos espermático dos caprinos da raça Bhuj Brasileira mostraram a presença de uma fina cápsula de tecido conjuntivo fibroelástico denso e uma camada subcapsular de tecido conjuntivo fibroelástico frouxo, não existido, nesta espécie, o tecido adiposo subcapsular que ocorre nos bovinos da raça Nelore (Viana 1986) e também nos bovinos de raças européia (Marçal 1988).

0 tecido adiposo que nos bovinos da raça Nelore encontra-se em situação subcapsular, acontece parcialmente nos suínos (Toniollo 1988). Nos ovinos da raça Corriedale (Carvalhal et al. 2000) é visto apenas como pequenos aglomerados também em posição subcapsular e constituindo a camada interna do mesoducto deferente, não podendo a ele ser atribuída qualquer função de isolante térmico como propuseram (Viana 1986, Toniollo 1988). Em eqüinos, pequenos acúmulos de tecido adiposo foram encontrados sob a cápsula funicular, no mesoduto deferente, e entre as estruturas vasculares (Sterman 1988, Santos 1992). Entretanto essa localização não foi confirmada no burro (Foz Filho et al. 1999) nem no jumento da raça Pega (Noronha et al. 2001).

0 ducto deferente dos caprinos da raça Bhuj Brasileira encontra-se isolado pelo mesodeferente, próximo ao funículo espermático, semelhante ao que acontece com os ovinos Corriedale (Carvalhal et al. 2000), suínos (Toniollo 1988), bovinos de origem européia (Marçal 1988), diferente do observado nos bovinos da raça Nelore (Viana 1986) e búfalos da raça Murrah (Machado 1992), cujo ducto ocupa posição intracapsular. Em alguns animais o ducto deferente se apresenta bastante distanciado do funículo espermático, como ocorre nos equinos (Sterman 1988, Santos 1992), burro (Foz Filho et al. 1999) e jumento da raça Pega (Noronha et al. 2001).

A artéria testicular tortuosa contida no funículo espermático e o plexo venoso existente merecem destaque pela presença de tecido conjuntivo fibroelástico denso intervascular, cujas fibras elásticas continuam com as adventícias destes 
vasos constituindo fator preponderante ao retorno sangüíneo da região testicular, como também as inúmeras comunicações e anastomoses destas veias que, desprovidas de válvulas, envolvem totalmente a artéria testicular. A ausência de válvulas no plexo pampiniforme já foi caracterizada em algumas espécies, nos ovinos da raça Corriedale (Carvalhal et al. 2000), suínos (Toniollo 1988), bovinos de origem européia (Marçal 1988), ratos (Gonçalves \& Borelli 2003), jumento da raça Pega (Noronha et al. 2001), burro (Foz Filho et al. 1999) e equinos (Sterman 1988, Santos 1992).

Os modelos de vinil dos vasos arteriais e venosos mostraram que o funículo espermático de caprinos da raça Bhuj Brasileira apresentou forma cônica; o que coincide parcial ou integralmente com a descrição da maioria dos autores que se referem a este funículo com possuindo o aspecto de cone alongado (Bimar 1888,), pirâmide (Bossi 1909), pacote alongado e cônico (Lesbre 1923), cone esguio (Nickel et al. 1979), eminência cônica larga (Wolfram 1942), ou em forma de cone (Viana 1986, Carvalhal et al. 2000, Almeida et al, 2008). Nestes modelos de acetato de vinil foi possível evidenciar ainda a artéria testicular completamente envolvida e entremeada às veias que formam o plexo venoso, com inúmeras e desordenadas sinuosidades, sem caracterizar disposição que pudéssemos identificar como voltas em espirais (Lubos et al. 1970, Schwarze \& Schroder 1970) ou com forma de novelo (Ellenberg \& Baum 1977).

O comprimento médio do segmento da artéria testicular contido no funículo espermático de Bhuj brasileira apresentou valores inferiores aos indicados para ovinos da raça Corriedale (Carvalhal et al. 2000). Estes dados nos fazem crer que a dimensão da artéria testicular contida no funículo espermático dos mamíferos deve variar em função das diferentes espécies e raças, bem como da idade do animal, como já proposto por Harrison (1948) e Sterman (1988). 0 trajeto sinuoso e a grande dimensão apresentada pelo trajeto da artéria testicular ao percorrer o funículo espermático representa fator indispensável não apenas para ocorrência das trocas térmicas como também para a diminuição da pressão arterial (Marçal 1988, Machado 1992, Barros 1995, Menezes 1995).

\section{CONCLUSÕES}

0 exame dos funículos espermáticos dos caprinos da raça Bhuj Brasileira mostraram características estruturais semelhantes a outros mamíferos, tais como, presença de cápsula de tecido conjuntivo fibroelástico denso, camada subcapsular de tecido conjuntivo fibroelástico frouxo, trajeto sinuoso da artéria testicular, ao percorrer o funículo espermático, veias testiculares constituintes do plexo venoso pampiniforme, desprovidas de válvulas e com amplas comunicações entre si.

Porém, características interespecíficas foram identificadas, tais como, ausência de uma camada de tecido adiposo subcapsular e comprimento do segmento da artéria testicular não apresentou diferença estatisticamente significante ao nível de $5,0 \%$, quando comparamos às médias correspondentes aos segmentos das artérias testiculares contidas no funículo espermático direito e esquerdo de dos caprinos da raça Bhuj Brasileira.

Agradecimentos.- À CAPES, pelo apoio financeiro, para realização do projeto.

\section{REFERÊNCIAS}

Almeida M.M., Assis Neto A.C., Penno A.K., Conde Júnior A.M. \& Carvalho M.A.M. 2008. Testicular arteries systematization based on different levels of scrotal configuration in caprines. Ciência Rural 38:1308-1312.

Barros M.R. 1995. Contribuição ao estudo do funículo espermático em cães SRD (Canis familiaris, Linnaeus 1758). Dissertação de Mestrado, Faculdade de Medicina Veterinária e Zootecnia, USP, São Paulo, SP. 56p.

Bimar N. 1888. Recherches sur la distribution des vaisseaux spermatiques chez divers mammifêres. Comptes Rendus de l'Academie des Sciences 106:80-83.

Bossi V. 1909. Angiologia, p.210-213. In: Bossi V., Caradonna G.B., Spampani G., Varaldi L. \& Zimmerl U. (Eds), Trattato di Anatomia Veterinaria. Vol.2. Francesco Vallardi, Milano.

Byers S.W. \& Glover T.D. 1984. Effect of scrotal insulation on the pitutarytesticular axis of the ram. J. Reprod. Fertility 71:23-31.

Carvalhal R., Borelli V. \& Miglino M.A. 2000. Estudo morfológico do funículo espermático em ovinos da raça Corriedale (Ovis aries L, 1758). Braz. J. Vet. Res. Anim. Sci. 37:348-354.

Courot M. \& Ortavant R. 1981. Endocrine control of spermatogenesis in the ram. J. Reprod. Fertility 30:47-60.

Cózer A.M.L., Godinho H.P. \& Fonseca V.O. 1979. Efeito de altas temperaturas sobre a espermatogênese de carneiros deslanandos em condições experimentais. Arqs Esc. Vet. Univ. Fed. Minas Gerais 31:147-154.

Dukes 2006. Fisiología dos Animais Domésticos. Guanabara Koogan, Rio de Janeiro. 954p.

Ellenberg W. \& Baum H. 1977. Handbuch der vergleichenden Anatomie der Haustiere. 18. Aufl. Springer Verlag, Berlin, p.523-30.

Foz Filho R.P.P., Fernandes Filho F. \& Borelli V. 1999. Características morfológicas do funículo espermático do burro (Equus asinus x Equus caballus). Braz. J. Vet. Res. Anim. Sci. 36:183-187.

Gonçalves A.M.M. \& Borelli V. 2003. Morphological aspects of the spermatic cord of mice (Mus musculus). Braz. J. Vet. Res. Anim. Sci. 40:62-70.

Hafez B. 2004. Reprodução Animal. Manole, Rio de Janeiro. 277p.

Harrison R.G. 1948. The comparative anatomy of the blood supply of the mammalian testis. Proc. Zoological Society of London 119:325-44.

Kishore P.N. \& Rao A.R. 1983. Effect of induced testicular degeneration on characteristics of bucks. Indian Vet. J. 60:281-286.

Latorre R.G. 1975. Estudio Anatomo-funcional del Aparato Reproductor del Toro. Universidade de Chile, p.40. (Apostila)

Lesbre F.X. 1923. Précis d'Anatomie Comparée des Animaux Domestiques. J.B. Baillière, Paris. 338p.

Lubos Holy G. \& Martinez J. 1970. Biología de la Reproducción Bovina. Instituto del Libro, La Habana. (Apud Latorre 1975)

Machado M.R.F. 1992. Contribuição ao estudo do funículo espermático em búfalos da raça Murrah (Bubalus bubalis Linnaeus, 1758). Dissertação de Mestrado, Faculdade de Medicina Veterinária e Zootecnia, USP, São Paulo, SP. 60p.

Machado Junior A.A.N., Miglino M.A., Menezes D.J.A., Assis Neto A.C., Leiser R., Silva R.A.B. \& Carvalho M.A.M. 2009. Influence of the bipartite scrotum on the testicular and scrotal temperatures in goats. Pesq. Vet. Bras. 29:797-802.

Marçal A.V. 1988. Estudo morfológico do funículo espermático em bovinos de origem européia (Bos taurus). Tese de Doutorado, Faculdade de Medicina Veterinária e Zootecnia, USP, São Paulo, SP. 65p.

Medeiros L.P., Girão R.N. \& Girão E.S. 1982. Produtividade de caprinos da raça Bhuj. Pesq. Agropec. Bras. 17:1371-1375.

Menezes L.S.P. 1995. Contribuição ao estudo do funículo espermático em gatos domésticos (Felix domestica Linnaeus, 1758). Dissertação de Mestrado, Faculdade de Medicina Veterinária e Zootecnia, USP, São Paulo, SP. $54 \mathrm{p}$.

Mieusset R., Quintana Casares P., Sanchez Partida L.G., Sowrbutts S.F., Zupp J.L. \& Setchell B.P. 1992. Effects of heating the testis and epididymis of ram by scrotal insulation on fertility and embryo mortality in ewes inseminated with frozen semen. J. Reprod. Fertility 94:337-344. 
Moule G.R. \& Waites G.M.H. 1963. Seminal degeneration in the ram and its relation to the temperature of the scrotum. J. Reprod. Fertility 5:433446.

Mucciolo R.G., Barbabé R.C. \& Barnabé V.H. 1974. Variações no quadro espermático de carneiros submetidos à degeneração testicular experimental. Revta Fac. Med. Vet. Zootec. Univ. São Paulo 11:155-177.

Nickel R., Schummer A., Seiferle E. \& Sack W.O. 1979. The Viscera of the Domestic Mammals. Verlag Paul Parey, Berlin. 315p.

Noronha P.B., Neto P.J. \& Borelli V. 2001. Aspectos morfológicos do funículo espermático de jumentos (Equus asinus Linnaeus, 1758) da raça Pêga. Braz. J. Vet. Res. Anim. Sci. 38:209-213.

Smith J.F. 1971. The effect of temperature on characteristics of semen of rams. Aust. J. Agric. Res. 22:481-490.

Santos A.L.Q. 1992. Contribuição ao estudo do funículo espermático de eqüinos S.R.D. (Equus cabalus Linnaeus, 1758). Dissertação de Mestrado, Faculdade de Medicina Veterinária e Zootecnia, USP, São Paulo, SP. 38p.
Schwarze E. \& Schröder L. 1970. Compendio de Anatomía Veterinaria: sistema visceral. Vol.2. Acribia, Zaragoza, p.254-525.

Sterman F.A. 1988. Contribuição ao estudo do funículo espermático em eqüinos da raça Puro Sangue Inglês. Tese de Doutorado, Faculdade de Medicina Veterinária e Zootecnia, USP, São Paulo, SP. 67p.

Toniollo G.H. 1988. Estudo morfológico do funículo espermático em suínos (Sus scrofa domestica Linnaeus, 1758). Tese de Doutorado, Faculdade de Medicina Veterinária e Zootecnia, USP, São Paulo, SP. 47p.

Viana W.G. 1986. Contribuição ao estudo do funículo espermático em bovinos da raça Nelore. Tese de Doutorado, Faculdade de Medicina Veterinária e Zootecnia, USP, São Paulo, SP. 35p.

Villares J.B. 1976. Bioclimatologia da reprodução animal. Anais Simpósio Nacional de Reprodução Animal, Colégio Brasileiro de Reprodução Animal, Belo Horizonte, p.192-215.

Wolfram W. 1942. Zur Anatomie der Arteria spermatica interna. Klinische Wochenschrift 21:1126-1127. 